\title{
Proposta de sistema agroflorestal em reserva legal de propriedade leiteira no Vale do Taquari/RS
}

O Vale do Taquari é uma região do estado do Rio Grande do Sul cuja produção de leite é uma das principais atividades econômicas desenvolvidas por pequenos produtores familiares em cooperação com empresas de laticínios, cuja renda com sua comercialização pode variar, pois recebe conforme qualidade do produto. Assim, o produtor vê a lavoura de grãos como complementação da renda, sendo que o método de plantio no RS é de monocultura, utilizando-se agrotóxicos para manutenção dos plantios, prática insustentável. O Sistema Agroflorestal (SAF) vem como uma proposta de manejo sustentável, podendo ser aplicado em áreas de Reserva Legal (RL), gerando-se renda em local não visualizado pelo produtor como rentável. Contudo, o objetivo do estudo é propor modelo de SAF na área de RL de uma propriedade produtora de leite no Vale do Taquari/RS. O método utilizado consiste em um roteiro de entrevistas com o produtor, análise de fertilidade do solo da RL, estudo florístico e conferência em bibliografias de cultivares adequados à área. Analisou-se que a área de RL possui um solo levemente ácido devido à predominância de $\mathrm{K}$ no solo, necessitando equilibrar com as substâncias básicas $\mathrm{Ca}$ e $\mathrm{Mg}$ em todas as Células Amostrais (CAs). Dos demais parâmetros de fertilidade, somente Fe não foi detectado. Para tanto, foram selecionadas espécies para adubação verde para recompor os nutrientes no solo, ao mesmo tempo que podem reduzir sua acidez. Foi observado que 29,5\% das espécies registradas na RL possuíam potencial agroflorestal com comercialização de frutos, sementes e outras partes botânicas. Para manter a originalidade da floresta, foram selecionadas as frutíferas nativas cerejas, guabiroba e morango-silvestre, bem como frutíferas exóticas mirtilo e fisális, para compor o SAF em RL. Para a área de possível expansão do SAF, foram selecionadas frutíferas nativas, espécies propostas pelo produtor rural (erva-mate, abacate e noz pecã) e hortaliças, além de espécie melífera para atrair polinizadores. Conclui-se que é possível realizar o manejo sustentável em área de RL por meio de SAF, onde este estudo pode mostrar à região uma nova forma de produção, além de oferecer à comunidade um produto diferenciado, sem uso de agrotóxicos, que preserva o meio ambiente e promove a qualidade de vida.

Palavras-chave: Agrofloresta; Manejo sustentável; Produção orgânica.

\section{Proposal for an agroforestry system in a legal dairy property reserve in Vale do Taquari/RS}

\begin{abstract}
Vale do Taquari is a region of the state of Rio Grande do Sul whose milk production is one of the main economic activities developed by small family farmers in cooperation with dairy companies, whose in RS is monoculture, using pesticides to maintain plantations, an unsustainable practice. The Agroforestry Sistem (AFS) comes as a proposal for sustainable management, and can be applied in RS is monoculture, using pesticides to maintain plantations, an unsustainable practice. The Agroforestry Sistem (AFS) comes as a proposal for sustainable management, and can be applied in
areas of Legal Reserve (LR), generating income in a place not seen by the producer as profitable. However, the objective of the study is to propose an AFS model in the LR area of a dairy farm in Vale do Taquari/RS. The method used consists of a script of interviews with the producer, analysis of soil fertility in LR, floristic study and verification of appropriate cultivars to the area in bibliographies. It was analyzed that the LR area has a slightly acidic soil due to the predominance of K in the soil, needing to balance with the basic substances Ca and Mg in all the Sample Cells (SC). Of the other fertility parameters, only Fe was not detected. For that, species were selected for green manure to recompose the nutrients in the soil, at the same time that they can reduce its acidity. It was observed that $29.5 \%$ of the species registered in the $L R$ had agroforestry potential with commercialization of fruits, seeds and other botanical parts. To maintain the originality of the forest, native cherry, guabiroba and wild strawberry fruits were selected, as well as exotic blueberry and physalis fruits, to compose the AFS in LR. For the area of possible expansion of the AFS, native fruit were selected, species proposed by the rural producer (verba mate, a ocado and pecan) and vegetables, in addition to honey species to attract pollinators.

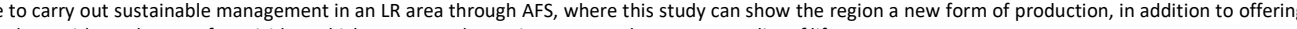
the community a differentiated product, without the use of pesticides, which preserves the environment and promotes quality of life.
\end{abstract}

Keywords: Agroforestry; Sustainable management; Organic production.

Topic: Agroecologia

Reviewed anonymously in the process of blind peer.

Ana Paula de Borba Morás (iD

Universidade do Vale do Taquari, Brasil

http://lattes.cnpq.br/5476707840992154

http://orcid.org/0000-0002-1535-8350

ana.moras@universo.univates.br

\section{Claudete Rempel (iD}

Universidade do Vale do Taquari, Brasil

http://lattes.cnpq.br/8340497822227462

http://orcid.org/0000-0001-8573-0237

crempel@univates.br

Jonas Bernardes Bica (it)

Universidade Feevale, Brasil

http://lattes.cnpq.br/6644682397199767

http://orcid.org/0000-0002-9762-4922

jonas.bica@universo.univates.br
Received: 01/01/2021

Approved: 25/01/2021
Patrícia Caye Bergmann (iD

Universidade do Vale do Taquari, Brasil

http://lattes.cnpq.br/8497886339173527

http://orcid.org/0000-0003-0081-9158

patricia.bergmann@universo.univates.br
Referencing this:

MORÁS, A. P. B.; REMPEL, C.; BICA, J. B.; BERGMANN, P. C.. Proposta de sistema agroflorestal em reserva legal de propriedade leiteira no Vale do Taquari/RS. Revista Ibero Americana de Ciências Ambientais, v.12, n.1, p.66-83, 2021. DOI: http://doi.org/10.6008/CBPC2179$\underline{6858.2021 .001 .0007}$ 


\section{INTRODUÇÃO}

O Vale do Taquari é uma região do estado do Rio Grande do Sul localizada na porção centro-oeste, formada por 36 municípios e pertencente ao Bioma Mata Atlântica (RIO GRANDE DO SUL, 2015). Sua área total é de 4.826,4 km² (FEIX et al., 2015), sendo 43 mil famílias trabalhando em meio rural, tendo a produção de leite como uma das principais atividades econômicas desenvolvidas por pequenos produtores familiares (AGOSTINI et al., 2018; STRATE et al., 2019). Conforme estudo desenvolvido pelo Instituto Brasileiro de Geografia e Estatística (IBGE, 2019) em 2018, para a região sul do país gerou-se uma média de 3.437 litros por animal por ano na propriedade, sendo no Vale do Taquari toda essa demanda comercializada para empresas de laticínios que trabalham em cooperação com o setor primário, onde a indústria recompensa com o valor de acordo com a quantidade e qualidade do produto, ou seja, o lucro do produtor pode ser variável (MACIEL et al., 2018).

Essa renda fixa é uma garantia ao pequeno produtor de certa forma, porém não suficiente para suprir as necessidades financeiras da propriedade, visto que os custos para a manutenção do rebanho voltados à nutrição animal são altos, e qualquer baixa no valor do litro do leite, como constatado por Valduga (2018), gera desequilíbrio da renda adquirida com esta atividade pecuária, gastando-se mais do que recebendo-se. Como outra maneira de obter rendimentos, o produtor observa a lavoura de grãos como uma boa alternativa, cultivando principalmente soja, conforme dados do Censo Agropecuário 2017 (IBGE, 2019).

O método utilizado no RS para produção de lavouras é o convencional, com grandes áreas monoculturais, utilizando-se dos pacotes tecnológicos desenvolvidos por empresas que ofertam a semente, fertilizante químico e agrotóxico para combater pragas e plantas consideradas daninhas (ÁVILA et al., 2015) Contudo, esta forma de produção afeta tanto a saúde do trabalhador envolvido como do ecossistema em seu entorno, acarretando em desequilíbrio da ecologia, contaminação e erosão do solo, além de poluir recursos hídricos essenciais (GREGIO et al., 2017). Sob o ponto de vista dos danos gerados pela produção convencional e da necessidade de produzir alimentos, torna-se necessário elaborar uma agricultura mais sustentável e que apresente menores impactos ambientais.

O Sistema Agroflorestal (SAF) vem como uma alternativa de produção de alimentos frente aos problemas descritos, visto que se baseia em um processo de ciclo fechado, onde o próprio sistema tem a capacidade de realizar o seu manejo de disponibilidade de nutrientes no solo, controle de pragas, uso adequado da energia solar e proteção dos recursos naturais sem uso de agroquímicos, fertilizantes e demais insumos agrícolas industrializados (EMBRAPA, 2017). Contudo, o produtor que adere a esta forma alternativa de produção não precisa diminuir sua renda com a manutenção da lavoura, e, ao mesmo tempo, pode gerar inúmeros produtos em igual área, obtendo rendimentos em todas épocas do ano devido à diversidade de cultivos. O propósito de um SAF é ser o mais semelhante possível à uma floresta natural, contemplando os estratos de vegetação, desde herbáceas até arbóreas, organizando-os de forma intercalada nas linhas de plantio, gerando consórcios entre as espécies (REICHERT et al., 2015).

Do ponto de vista ambiental, o SAF pode funcionar também como corredor ecológico entre 
fragmentos florestais para permitir o fluxo da fauna, dispersão de sementes e desenvolvimento do ecossistema local, visto que inclui a vegetação arbóreo-arbustiva nativa da região de implantação (JESUS et al., 2018). O SAF diverso remete a uma floresta bem estruturada, onde disponibiliza a própria biomassa de nutrientes por meio dos recursos que pode gerar, como matéria orgânica e nutrientes providos das folhas de arbóreas caducas (PARDON et al., 2017), incrementa a qualidade da água para proteger a fauna e a flora, além de proteger o solo contra processos erosivos devido à sua cobertura por matéria vegetal (NAIR, 2007).

De acordo com a Lei Federal no 12.651/2012 (BRASIL, 2012), deve ser mantida uma porcentagem da área total da propriedade para o desenvolvimento da mata nativa, sendo esta conhecida como Reserva Legal (RL); no RS, em ambientes de Bioma Mata Atlântica, essa porcentagem se refere a $20 \%$. Na mesma legislação consta que está RL pode ser utilizada para o manejo sustentável, fornecendo um ambiente propício para a instalação de um SAF. Para o pequeno produtor familiar, poder usufruir um pouco mais de suas terras e de forma ecologicamente correta utilizando o SAF torna-se uma boa opção para incrementar a renda familiar. No contexto atual, e buscando potencializar a possibilidade preservação das áreas de RL, e ao mesmo tempo promover tais áreas para a produção sintrópica, o objetivo deste trabalho é propor um modelo de Sistema Agroflorestal em área de RL de uma propriedade produtora de leite em área rural no Vale do Taquari/RS.

\section{MATERIAIS E MÉTODOS}

A pesquisa consistiu no estudo de caso de uma propriedade produtora de leite localizada na região do Vale do Taquari/RS (Imagem 1), cuja área de RL foi analisada. As coordenadas do local não estão informadas a fim de evitar a exposição do proprietário da área. Para tanto, iniciou-se a pesquisa com a realização de um roteiro de entrevistas com o proprietário, aprovado pelo Comitê de Ética em Pesquisa (Coep) da Universidade do Vale do Taquari Univates, sob número CAAE 28860820.3.0000.5310.

Para a elaboração do questionário foram observadas premissas da metodologia de Franke et al. (2000) quanto ao planejamento, implantação e monitoramento de sistemas agroflorestais. Esta etapa do estudo concentrou-se em introduzir o assunto sobre SAF ao produtor e obter sua perspectiva quanto a esta alternativa de produção de alimentos. Os questionamentos objetivaram identificar quais os cultivares que o entrevistado demonstraria interesse em produzir caso fosse implantar o SAF, ofertando opções, e quais ele acredita ser de mais fácil comércio conforme seus conhecimentos da região, além de questionar se lhe interessaria a formulação de produtos da agroindústria familiar.

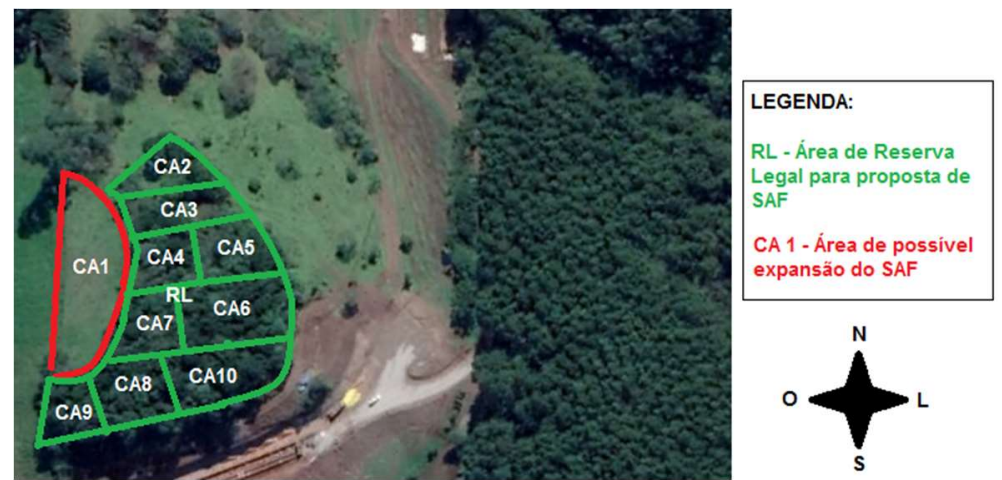

Imagem 1: Localização da área para propor o SAF. Fonte: Adaptado de Google Earth. 
A análise do solo foi efetuada realizando-se a coleta de amostra na $R L$ da propriedade, seguindo as recomendações de Arruda et al. (2014) quanto à amostragem de solos para verificar sua fertilidade. O solo da região é classificado como Chernossolo Háplico Órtico típico, conforme estudo realizado por Streck et al. (2008). Para tanto, dividiu-se a área total em 10 Células Amostrais (CAs) aleatórias na forma de amostras compostas, contendo de 10 a 15 sub amostras simples, coletando-se à profundidade superficial de 0-10 cm. Cada amostra designou 10 situações distintas na condição do solo, sendo elas Pastagem (CA 1) Borda mata x Pastagem em terreno plano (CA 2), Borda mata x Pastagem em terreno acentuado (CA 3), Interior de mata com acesso do gado (CA 4), Interior mata em terreno acentuado (CA 5), Interior mata sem acesso gado (CA 6), Interior mata em terreno plano (CA 7), Borda mata em terreno acentuado (CA 8), Mata com avanço da pastagem (CA 9) e Borda mata em terreno plano (CA 10). Araújo et al. (2012) orienta a amostragem de solo superficial, visto que este horizonte apresenta uma grande atividade microbiológica com a decomposição da matéria orgânica disposta no solo, liberando nutrientes para incrementar sua fertilidade. As amostras compostas de solo foram homogeneizadas com uma pá em um balde, e uma porção de aproximadamente $500 \mathrm{~g}$ de cada amostra foi acondicionada em saco estéril, identificando-a quanto às características do ponto amostral.

Posterior ao acondicionamento, as amostras de solo foram encaminhadas para a Central Analítica da Universidade de Santa Cruz do Sul (UNISC) a fim de realizar a análise química completa do solo coletado. Os parâmetros analisados foram Teor de Argila (\%), Classe textural em solo, pH em água, Acidez trocável por Alumínio $\left(\mathrm{Al}^{+3}\right)$, Acidez Potencial por $\mathrm{H}^{+}+\mathrm{Al}^{3+}$, Fósforo $(\mathrm{P})$ disponível, cátions Potássio $(\mathrm{K})$, Cálcio (Ca) e Magnésio (Mg) trocáveis, Soma de Bases (SB), Capacidade de Troca Catiônica (CTC) efetiva e ao pH 7, 0, disponibilidade dos macro e micronutrientes Enxofre (S), Zinco (Zn), Cobre (Cu), Boro (B), Manganês (Mn), Ferro (Fe), Cloro (Cl) e Sódio (Na), Teor de Matéria Orgânica (M.O.), Teor de Saturação de CTC por alumínio $(\mathrm{m})$, de Bases $(\mathrm{V})$ e de potássio $(\mathrm{K})$, além de relações entre nutrientes.

O estudo florístico foi realizado pelo método de caminhamento (FILGUEIRAS et al., 1994) na RL da propriedade para adquirir conhecimento da diversidade de espécies que se encontram na área, bem como sua frequência de surgimento na vegetação, avaliando-as quanto ao potencial agroflorestal que apresentam. A identificação ocorreu in loco e, quando da não-identificação a campo, coletou-se o material botânico para posterior identificação em laboratório, utilizando-se bases de dados e ferramentas bibliográficas, como Sobral et al. (2013), para auxiliar na identificação, considerando a APG IV (APG et al., 2016) para a descrição correta dos nomes científicos e famílias das espécies vegetais.

Para a modelagem do SAF considerou-se os cultivares indicados pelo entrevistado e sua capacidade de produção na área de estudo, bem como avaliou-se as espécies encontradas na análise florística e a condição nutricional do solo, além de observar características visuais obtidas in loco quanto à luminosidade e morfologia do solo nas CAs. Para a indicação dos cultivares adequados e formas de plantio, fez-se consulta em bibliografias, tendo-se como referência os princípios da agroecologia conforme indicam Altieri (2018) e Caporal et al. (2002), ressaltando que a proposta de modelo agroflorestal é única para a área a ser estudada, visto que cada ambiente possui suas particularidades. 


\section{RESULTADOS E DISCUSSÃO}

\section{Roteiro de entrevista}

O questionamento inicial do roteiro de entrevistas fora em relação à obtenção de renda, em que o produtor informou adquirir através da venda do leite, pomar de frutíferas e criação de porcos. Dos cultivos para uso da família, identificou atualmente a produção de milho destinada à fabricação de ração para nutrição do gado leiteiro, pois o custo é inferior caso fosse comprado o insumo alimentar pronto, além de pastagem, como os cereais aveia e trigo, e hortaliças em geral. Em estudo desenvolvido por Tejero et al. (2016) na região Sul do Brasil, questionando produtores de milho que destinam sua produção à ração, indagou-se quanto ao manejo adotado na lavoura. Os resultados do estudo apontaram que $100 \%$ faz a adubação química e metade controla quimicamente as pragas e plantas indesejáveis na cultura; da produção de trigo, Bona et al. (2016) afirmaram a necessidade de intervenção no solo a ser cultivado com fertilização para que o cereal se desenvolva. No cultivo de aveia, Sartori et al. (2018) indicaram a importância de se manejar o solo através da adição de nitrogênio, comumente aplicado na forma química, para que a planta tenha bom crescimento, já que é utilizada para obtenção do pasto para alimentação do gado. Analisando os cultivares da propriedade e suas necessidades de manejo, é previsto que demanda do uso de insumos agrícolas, visto que são necessários para manter a viabilidade da lavoura e, assim, disponibilizar alimento aos animais. Caso ocorra alguma perda na produção, o produtor é obrigado a dispender um valor não previsto de sua renda para nutrição animal. Essa condição retoma à questão da renda instável do leite, e qualquer mudança de custos poderá interferir diretamente na renda familiar.

Ao questionar sobre o conhecimento em relação à produção no formato SAF, após a explicação dada pelos autores, o produtor reconheceu o modelo e indagou já ter observado este método anteriormente, pela integração lavoura-floresta-pecuária. Ao ser perguntado se o SAF é uma boa alternativa para produção de alimentos, o mesmo informou que sim, porém, em sua visão, é eficaz a longo prazo, com produção de cultivos mais arbóreos, como erva-mate, abacate, noz-pecã, jabuticaba, goiaba e figo, e rasteiros, como amendoim e batata-doce. Quanto aos cultivos citados, o mesmo apontou a produção de erva-mate, abacate e noz pecã como as mais rentáveis, pela facilidade de manejo e existência de mercado. Segundo dados do último Censo Agropecuário (IBGE, 2019), em 2017 haviam somente três unidades de produção de erva-mate convencional. Ou seja, esta indicação de cultivar pelo produtor pode ser muito viável para o SAF, visto que a competitividade de produção no município é baixa e a forma de produção é diferenciada, o que pode valorizar o produto e incrementar os lucros ao vendê-lo para ervateiras, como mostra estudo de Morganti Júnior et al. (2020), cuja produção sustentável de erva-mate foi promissora tanto para na questão socioeconômica aos agricultores como ambiental da região que o projeto fora implementado. Quanto à produção de abacate e noz-pecã foram registradas no mesmo Censo Agropecuário (IBGE, 2019) uma e seis propriedades produtoras, respectivamente, números também considerados baixos e de mínima competitividade, o que amplifica o valor de comercialização. O produtor foi questionado se, caso implantasse o SAF, teria interesse em gerar produtos da agroindústria familiar, e o mesmo não demonstrou interesse. 
Em relação à última questão, de existir ou não uma feira do produtor no município, o mesmo informou que há e já tentou ingressar, mas sem sucesso, afirmando a dificuldade em poder participar. Neste caso, em uma oportunidade de produzir alimentos através de sistema alternativo, como o SAF, o produtor teria que disponibilizar seus cultivares de outra forma para o mercado consumidor. Silva et al. (2018), em sua revisão bibliográfica sobre a comercialização de produtos orgânicos, ofertam algumas opções de venda adotadas por produtores no país, como a montagem de cestas com produtos variados e sua entrega a domicílio, revenda em lojas específicas voltadas à alimentação natural, além de, até mesmo, comercialização para supermercados e atacados, conforme a quantidade de produção. Strate et al. (2018) afirmam em seu estudo com produtoras familiares em Teutônia/RS, que as entrevistadas optam por a comercialização dos cultivares, provenientes de seus quintais produtivos sustentáveis, em programas governamentais, como o Programa Nacional de Alimentação Escolar (PNAE), onde ao menos 30\% da compra de insumos alimentares deve ocorrer de forma direta com agricultores familiares (BRASIL, 2009).

\section{Solo}

A amostragem de solo possibilitou designar nove situações distintas e ocorrentes na RL da propriedade, cuja área é de 0,42 ha, e um ambiente adjacente passível de expansão da RL através do SAF, totalizando as 10 CAs. Apesar da diferenciação nas amostras, todas as CAs apresentaram valores semelhantes quanto aos parâmetros físico-químicos do solo, montando-se uma média.

Tabela 1: Média de valores dos parâmetros físico-químicos da área de estudo.

\begin{tabular}{llllllllllllllllllll}
\hline & Argila & Classe & $\begin{array}{l}\text { pH } \\
\text { H20 }\end{array}$ & H+Al & Ca & Mg & K & P & S & $\begin{array}{l}\text { CTC } \\
\text { Bases }\end{array}$ & $\begin{array}{l}\text { CTC } \\
\text { Efetiva }\end{array}$ & M.O. & Ca/Mg & (Ca+Mg)/K & Zn & Cu & B & Mn \\
\hline RL & 19.8 & 3.6 & 5 & 8 & 9.7 & 2.6 & 321 & 33 & 25.5 & 62.7 & 13.2 & 12.3 & 3.8 & 16.8 & 27.2 & 0.8 & 1.5 & 91.3 \\
CA1 & 28 & 3 & 5.5 & 5.9 & 6.6 & 3.5 & 474 & 38 & 19 & 65.7 & 11.4 & 9.4 & 1.9 & 8.4 & 43.3 & 3.5 & 0.6 & 44 \\
\hline
\end{tabular}
Unidades: Argila, CTC por bases, M.O.: \%; H+Al, Ca, Mg, Na, P, CTC Efetiva, $\mathrm{Ca} / \mathrm{Mg},(\mathrm{Ca}+\mathrm{Mg}) / \mathrm{K}: \mathrm{cmolcdm}-3 ; \mathrm{K}, \mathrm{S}, \mathrm{Zn}, \mathrm{Cu}$, B, Mn: mgdm-3.

Quanto às propriedades físicas do solo, apesar das amostras indicarem teores de argila relativamente baixos, as classes texturais permitem definir que se tratam de solos argilosos (Classe 3) e médio argilosos (Classe 4), conforme indicação do triângulo de classe textural SiBCS13 proposta por ten Caten et al. (2015), o que está de acordo com a classificação do solo da região. Essa caracterização afirma a possibilidade de produzir cultivares no local, pois de acordo com Santos et al. (2018), trata-se de uma terra de coloração escura com quantidades adequadas de matéria orgânica disponível, bem como de argila, e sua condição de fina granulometria permite o acúmulo de compostos essenciais para o desenvolvimento das plantas, principalmente nutrientes, o que afere fertilidade ao solo.

Para todas as células amostrais o pH em água do solo se mostrou de caráter ácido, variando de 4,5 a 5,5, cuja média na área florestada indicou maior acidez que na CA 1, de pastagem. Ao mesmo tempo, não foi registrada a presença de alumínio trocável (Al) nas amostras, o que é um bom resultado, tendo-se que esse composto interfere diretamente no desenvolvimento de significativa parte das plantas por seu efeito tóxico (NOLLA et al., 2015). O pH ácido do solo está ligado à existência de acidez potencial pelo composto hidrogênio 
(H), com níveis variando de 4,8 a 12,1 $\mathrm{cmol}_{c} \mathrm{dm}^{-3}$, cuja média é maior que na área de pastagem. Solos tropicais, semelhantes ao do atual estudo, possuem um caráter mais ácido, em torno de 5,6, porém, o maior aporte de matéria orgânica, em conjunto com a atividade microbiana, torna-se fundamental para regular o pH e permitir a permanência de bases trocáveis no solo, os nutrientes, cujos substituem o $\mathrm{H}$ e aumentam a fertilidade (PRIMAVESI, 2016; VILLAR, 2007).

Analisando-se os valores médios dos macronutrientes $\mathrm{Ca}, \mathrm{Mg}$ e $\mathrm{K}$, os mesmos apresentam valores adequados no solo superficial, quando comparados aos valores padrão instaurados por Sobral et al. (2015). Em estudo desenvolvido por Silva et al. (2007), fez-se uma análise da fertilidade de Chernossolo em mata nativa na camada mais superficial, cujos valores dos respectivos nutrientes foram semelhantes, sendo 9,4, 2,52 e 0,41 $\mathrm{cmol}^{\mathrm{c}} \mathrm{dm}^{-3}$. Porém, se levar em consideração que a concentração desses nutrientes se inverte no organismo vegetal, os níveis de $\mathrm{K}$ registrados se apresentam em excesso, conforme valores padrão indicados por Benites et al. (2009) em profundidade de 0-10 cm para esse composto, possivelmente vindo comprometer a absorção das demais substâncias pelas plantas. Essa questão reforça a necessidade de incrementar matéria orgânica no solo, principalmente de biomassa rica em bases como $\mathrm{Ca}$ e $\mathrm{Mg}$. O Na, que faz parte do cálculo de CTC, não foi detectado nas amostras, implicando em um solo mais saudável, visto que excesso de sais podem interferir na absorção radicular das plantas, bem como comprometer a formação de agregados (LOSEKANN, 2009), imprescindíveis para um solo de qualidade.

Os valores adquiridos de saturação por bases variaram de $54,7 \%$ a $71,8 \%$, reforçando a condição ácida do solo, pois conforme Sobral et al. (2015), o padrão mínimo deste parâmetro, a fim de evitar a necessidade de calagem, é 70\%, aferindo que quanto menor a ocupação de partículas básicas no solo, maior é a chance de ácidas ocuparem este espaço. Ao considerar o valor médio deste parâmetro percebe-se que o percentual é próximo, mas precisa ser incrementado por meio do aporte de compostos básicos no solo. A CTC efetiva variou de 11,1 a 16,1 $\mathrm{cmol}_{\mathrm{c}} \mathrm{dm}^{3}$, quantidade adequada para incorporar nutrientes e permitir a ciclagem dos mesmos (SOBRAL et al., 2015). Ao comparar com estudo desenvolvido por Silva et al. (2007), em sua camada mais superficial a porcentagem de saturação por bases foi maior, com $82 \%$, mas a CTC foi inferior, indicando $12,33 \mathrm{cmol}_{\mathrm{c}} \mathrm{dm}^{3}$.

A disponibilidade de MO é adequada se considerar os padrões de fertilidade propostos por Sobral et al. (2015), cujas porcentagens se apresentaram de 8,8 a 13,9\% nas amostras. O percentual médio de MO na RL foi maior se comparado ao da pastagem (CA 1), resultado já esperado devido à área florestada dispor suas estruturas botânicas no solo, formando a serapilheira e, pela atividade microbiana, incrementando MO no solo. Em relação à quantidade de $\mathrm{P}$, importante macronutriente responsável pelo crescimento $\mathrm{e}$ desenvolvimento das plantas (BORGES et al., 1997), apenas na CA 2 seu teor foi médio, sendo adequado em todos os demais pontos, de acordo com a quantidade mínima indicada por Sobral et al. (2015). Porém, por ser uma substância imóvel (BORGES et al., 1997), possíveis intempéries, como o acesso do gado observado em algumas porções do fragmento florestal e chuvas podem ocasionar em sua movimentação, comprometendo sua disponibilidade.

O equilíbrio de $\mathrm{Ca} / \mathrm{Mg}$ está garantido nas CAs 3 a 10, visto que o valor padrão de normalidade é de 3 
a 6 conforme Primavesi (2016). Porém, ao considerar o $\mathrm{K}$, a relação $(\mathrm{Ca}+\mathrm{Mg}) / \mathrm{K}$ se mostra em desequilíbrio, onde ao comparar com o padrão instituído por Benites et al. (2009), é baixo, necessitando um maior aporte de $\mathrm{Ca}$ e $\mathrm{Mg}$ para regular os teores. $\mathrm{O}$ enxofre, mesmo na camada de 0 a $10 \mathrm{~cm}$ que comumente está integrado em menores quantidades, apresentou bons resultados em todas as células amostrais, visto que seu valor atingiu níveis superiores $5 \mathrm{mg} / \mathrm{dm}^{3}$, limite mínimo estabelecido por CQFS (2004). As médias de valores de macronutrientes obtidos nas análises de solo seguiram a ordem $\mathrm{K}>\mathrm{P}>\mathrm{S}>\mathrm{Ca}>\mathrm{Mg}>\mathrm{Na}$.

Quanto aos valores registrados dos micronutrientes $\mathrm{Zn}, \mathrm{Cu}, \mathrm{B}$ e $\mathrm{Mn}$, todos teores encontram-se em condição "Alta" para produção de cultivares, se seguir padrões estabelecidos por CQFS (2004), onde levandose em consideração as médias de valores nas $\mathrm{CAs}$, constatou-se que seguem a ordem $\mathrm{Mn}>\mathrm{Zn}>\mathrm{B}>\mathrm{Cu}>\mathrm{Fe}, \mathrm{Cl}$. Não foram detectados os compostos $\mathrm{Fe}$ e $\mathrm{Cl}$ nas amostras, ou suas quantidades são muito baixas neste horizonte do solo que não foram detectadas na análise. É um resultado aceitável, visto que podem ser considerados tóxicos à vegetação (FAQUIN, 2005), uma vez que o Fe em excesso produz efeito de "bronzeamento" no solo, impedindo o correto desenvolvimento das plantas (CQFS, 2004). Porém, o incremento do Fe é importante para a manutenção de plantas, visto que tem papel fundamental nas funções das enzimas vegetais (FAQUIN, 2005). Estudo desenvolvido em Chernossolo por Silva et al. (2006) registrou maiores valores de micronutrientes na camada mais superficial do solo, onde o teor de argila é menor, indicando a importância do estudo desses compostos no primeiro horizonte do solo.

\section{Levantamento florístico}

A análise florística registrou um total de 44 espécies arbóreas e 3 não-identificadas, pertencentes a 28 famílias botânicas (Tabela 2). A frequência de surgimento das espécies $A$. angustifólia e $C$. vernalis foi maior, com $100 \%$ de ocorrência nas CAs, seguidas por A. edulis, C. silvestris e $E$. uniflora em $88,8 \%$ das amostras com vegetação. Estudo desenvolvido na mesma região obteve resultados semelhantes, sendo as espécies $A$. edulis, $C$. vernalis e $E$. uniflora presentes entre as espécies mais frequentes, aferindo à região certa homogeneidade de espécies (REMPEL et al., 2018). Foram visualizadas a campo muitos exemplares de C. vernalis, principalmente em porções rochosas, como em partes das CAs 2 e 3. De acordo com estudo desenvolvido por Almeida et al. (2015), a presença desta espécie pode auxiliar na estabilização de áreas declivosas e com solo pouco profundo, permitindo aferir às CAs citadas a necessidade por cultivares de raízes com hábito superficial.

De todas espécies identificadas, 13 (29,5\%) possuem potencial agroflorestal para comércio, sendo elas $A$. angustifólia por meio de suas sementes, E. uniflora, C. xanthocarpa, Citrus sp., E. japônica, S. romanzoffiana, A. neosalicifolia, A. sylvatica, C. iguanaea, E. involucrata, A. edulis e V. megapotamica pela comercialização dos frutos (KINUPP, 2007; BIONDO et al., 2018; LEAL et al., 2018; SCHUSTER, 2015) , além de U. baccifera (Urtiga) com a possibilidade de ingestão das folhas, frutos e sementes após preparação por branqueamento (BIONDO et al., 2018). A fim de preservar a originalidade da floresta, é possível aproveitar as espécies potenciais já existentes e aumentar sua capacidade de produção, incrementando o número de indivíduos de $C$. xanthocarpa e E. involucrata, comercializando seus frutos. Essas espécies são adaptadas a 
ambientes sombreados (LIMA, 2018; DEGENHARDT et al., 2007), podendo facilmente se desenvolver em todas as CAs florestadas, de 2 a 10.

Tabela 2: Espécies arbóreas registradas no estudo florístico.

\begin{tabular}{|c|c|c|}
\hline FAMÍLIA & ESPÉCIE & NOME POPULAR \\
\hline \multirow{2}{*}{ Annonaceae } & Annona neosalicifolia H.Rainer & Araticum \\
\hline & Annona sylvatica A.St.-Hil. & Araticum \\
\hline Aquifoliaceae & Ilex theezans Mart. ex Reissek & Caúna \\
\hline Araucariaceae & Araucaria angustifólia (Bertol.) Kuntze & Araucária \\
\hline Arecacecae & Syagrus romanzoffiana (Cham.) Glassman & Jerivá \\
\hline Asteraceae & Dasyphyllum spinescens (Less.) Cabrera & Sucará \\
\hline Bignoniaceae & Handroanthus pulcherrimus (Sandwith) Mattos & Ipê-amarelo \\
\hline Boraginaceae & Cordia americana (L.) Gottschling \& J.S.Mill. & Guajuvira \\
\hline Cannabaceae & Celtis iguanae (Jacq.) Sarg. & Esporão-de-galo \\
\hline Cardiopteridaceae & Citronela paniculata (Mart.) R.A.Howard & Congonha \\
\hline Celastraceae & Monteverdia aquifolia (Mart.) Biral & Espinheira-santa \\
\hline Erythroxylaceae & Erythroxylum deciduum A.St.-Hil. & Cocão \\
\hline \multirow{4}{*}{ Euphorbiaceae } & Sapium glandulosum (L.) Morong & Leiteiro \\
\hline & Gymnanthes klotzschiana Müll.Arg. & Branquilho \\
\hline & Machaerium stipitatum Vogel & Farinha-seca \\
\hline & Myrocarpus frondosus Allemão & Cabreúva \\
\hline \multirow[t]{3}{*}{ Fabaceae } & Parapiptadenia rigida (Benth.) Brenan & Angico-vermelho \\
\hline & Apuleia leiocarpa (Vogel) J.F.Macbr. & Grápia \\
\hline & Muellera campestris (Mart. ex Benth.) M.J. Silva \& A.M.G. Azevedo & Rabo-de-bugio \\
\hline \multirow[t]{2}{*}{ Lamiaceae } & Vitex megapotamica (Spreng.) Moldenke & Tarumã \\
\hline & Ocotea puberula (Rich.) Nees & Canela-guaicá \\
\hline \multirow{3}{*}{ Lauraceae } & Nectandra oppositifolia Nees & Canela-ferrugem \\
\hline & Nectandra lanceolata Nees & Canela-amarela \\
\hline & Nectandra megapotamica (Spreng.) Mez & Canela-preta \\
\hline Malvaceae & Luehea divaricata Mart. \& Zucc. & Açoita-cavalo \\
\hline Meliaceae & Melia azedarach L. & Cinamomo \\
\hline \multirow[t]{2}{*}{ Moraceae } & Ficus luschnathiana (Miq.) Miq. & Figueira \\
\hline & Eugenia uniflora L. & Pitangueira \\
\hline \multirow[t]{2}{*}{ Myrtaceae } & Campomanesia xanthocarpa (Mart.) O.Berg & Guabiroba \\
\hline & Eugenia involucrata DC. & Cerejeira \\
\hline \multirow{2}{*}{ Primulaceae } & Myrsine umbellata Mart. & Capororoca \\
\hline & Myrsine coriacea (Sw.) R.Br. ex Roem. \& Schult. & Capororoca \\
\hline Rhamnaceae & Hovenia dulcis Thunb. & Uva-do-japão \\
\hline \multirow[t]{2}{*}{ Rosaceae } & Eriobothrya japônica (Thunb.) Lindl. & Ameixa-amarela \\
\hline & Zanthoxylum rhoifolium Lam. & Mamica-de-cadela \\
\hline \multirow[t]{2}{*}{ Rutaceae } & Zanthoxylum kleinii (R.S.Cowan) P.G.Waterman & Mamica-de-cadela \\
\hline & Citrus sp. & Bergamoteira \\
\hline \multirow[t]{2}{*}{ Salicaceae } & Casearia sylvestris Sw. & Chá-de-bugre \\
\hline & Cupania vernalis Cambess. & Camboatá-vermelho \\
\hline \multirow[t]{2}{*}{ Sapindaceae } & Allophylus edulis (A.St.-Hil. et al.) Hieron. ex Niederl. & Chal-chal \\
\hline & Matayba elaeagnoides Radlk. & Camboatá-branco \\
\hline Solanaceae & Solanum mauritianum Scop. & Fumeiro \\
\hline Styracaceae & Styrax leprosus Hook. \& Arn. & Carne-de-vaca \\
\hline Urticaceae & Urera baccifera (L.) Gaudich. ex Wedd. & Urtigão-bravo \\
\hline- & Sem identificação 1 & - \\
\hline- & Sem identificação 2 & - \\
\hline- & Sem identificação 3 & - \\
\hline
\end{tabular}

A família com maior número de espécies foi Fabaceae, com cinco indivíduos, sendo estas conhecidas por leguminosas, possuindo capacidade de interagir com rizóbios pelas raízes, aferindo-lhes a função de fixar $\mathrm{N}$ atmosférico no solo, disponibilizando à vegetação presente (SOUZA et al., 2019). Rempel et al. (2018) e Markus et al. (2018), que estudaram a florística de propriedades da mesma região, apresentaram resultados semelhantes, tendo-se a família Fabaceae como a mais diversa. A subfamília Faboideae possui essa característica em maior intensidade (SOUZA et al., 2019), sendo $M$. frondosus a única espécie registrada na área de estudo, presente em seis $(66,6 \%)$ das nove CAs com vegetação florestal. Também, em estudo 
desenvolvido por Martins et al. (2019), os gêneros Lonchocarpus, Machaerium e a espécie $P$. rigida, da família Fabaceae, são importantes leguminosas arbóreas fixadoras de $\mathrm{N}$ no solo, aferindo às espécies registradas na RL M. stipitatum, M. campestris - antiga Lonchocarpus campestris (REFLORA, 2020) - e à própria P. rigida uma indicação de que nas CAs em que foram registradas há disponibilidade de $\mathrm{N}$ à vegetação. Devido à não efetivação da análise deste nutriente é importante aferir características presentes na ecologia do fragmento, reforçando com bibliografias, a fim de identificar possíveis determinações do mesmo no solo. Contudo, por meio das informações sobre as espécies arbóreas ocorrentes no fragmento, pode-se determinar que nas CAs de ocorrência das espécies e gêneros citados, neste caso as CAs de 2 a 10, existam quantidades adequadas de $\mathrm{N}$ fixadas no solo em toda extensão florestal.

Para o reaproveitamento do $\mathrm{N}$ atmosférico com maior intensidade podem ser implantadas leguminosas herbáceas, sendo indicada a espécie Canavalia ensiformis (L.) DC. (feijão-de-porco), visto que é adaptada a ambientes sombreados (AQUINO et al., 2005), podendo ser cultivada nas porções internas da RL. Demais nutrientes que este adubo verde é capaz de reciclar são $\mathrm{Ca}, \mathrm{Mg}$, Fe e Cu conforme resultados obtidos por Rayol et al. (2012). Também é orientado o cultivo do adubo verde de verão Vigna unguiculata (L.) Walp. (feijão-caupi, feijão-fradinho), devido aos seus múltiplos usos, visto que é capaz tanto de incorporar $\mathrm{N}$ no solo através de sua biomassa, quanto de servir como forrageira para alimento ao gado devido aos seus níveis nutricionais e proteicos adequados, além de ser possível a sua produção para colheita de sementes, gerando um potencial de até $2500 \mathrm{Kg} / \mathrm{ha}$ de rendimento na região Sul do Brasil (BEVILAQUA et al., 2007). Visto que a RL é um ambiente florestal, há menor incidência de luz, sendo estas herbáceas tolerantes à baixa luminosidade nas porções internas do fragmento, incrementando no tamanho de suas folhas, bem como na quantidade de biomassa que posteriormente será incorporada ao solo (LOURENÇO et al., 2017).

A fim de indicar cultivares com potencial de implantação no modelo de SAF, a espécie Vaccinium sp., conhecida como mirtilo de variação rabbiteye, pode ser uma opção diferenciada para a região, visto que são poucos os produtores no estado, onde o Censo Agropecuário de 2017 (IBGE, 2019) não apresenta como um produto de lavoura permanente específico, mas sim como outros devido à baixa quantidade de área plantada. A planta apresenta raízes superficiais, é adaptada a solos com pH ácido, aceita solos rasos, além de ocupar o estrato arbustivo de uma floresta (ANTUNES et al., 2006), facilitando a colheita e permanecendo a certo sombreamento. Este cultivar necessita do macronutriente $\mathrm{N}$ em grandes quantidades, além de um solo mais ácido, o que foi detectado nas análises da RL, além de uma média de 300 horas de frio anuais, cujo município onde a área está inserida garante uma média de 1725,6 horas de frio por ano (WREGE et al., 2012). Se seguido o planejamento de enriquecimento do solo por meio da adubação verde, o mirtilo é uma opção de cultivar para se implantar na modelagem de SAF.

A espécie Rubus spp., conhecida como morango-silvestre, pode ser outra opção de cultivo para rendimentos ao produtor. $\mathrm{O}$ gênero desta espécie nativa costuma ocorrer em beiras de terrenos, resistindo a alterações hídricas e cobrindo o solo por seu caráter arbustivo, permanecendo no estrato inferior da floresta (ANTUNES et al. 2004). Picolotto et al. (2012) analisaram o solo de uma área experimental com cultivo da morango-silvestre, cujos nutrientes da atual pesquisa estavam com valores acima da bibliografia 
citada, exceto de P nas CAs 2, 8, 9 e 10, Na que não foi detectado em nenhuma CA, Cu nas CAs 5 e 9 e Fe não registrado nas CAs, cujos foram menores. $\mathrm{O}$ pH do solo da atual pesquisa apresentou-se mais ácido ao comparar com os resultados dos autores citados. Contudo, as diferenças são mínimas, tornando-se possível corrigir esses valores com o incremento de espécies de adubação verde no estrato herbáceo, cujas auxiliam na reposição dos componentes nutricionais, bem como adicionam M.O. no solo e aumentam a atividade microbiana (PRIMAVESI, 2016).

Outro cultivar para integrar o SAF é a espécie arbustiva Physalis peruviana L. (fisális), fruto fino consumido devido aos benefícios medicinais, além de ser adquirido por confeitarias a fim de compor seus produtos (RODRIGUES, 2018). Seus frutos são muito valorizados, mesmo por seu cultivo ser fácil, bem resistente a mudanças de clima e por ocupar os mais diversos ambientes, além de perpetuar a produção em bom estado por um longo período (MUNIZ et al., 2014), tornando-a espécie potencial de se implantar em um SAF.

Para a deficiência de $\mathrm{P}$ em algumas CAs à espécie indicada morango-silvestre é possível realizar o plantio inicial de Mucuna pruriens (L.) DC. - anteriormente M. aterrima - (mucuna-preta), visto que suporta sombreamento de 50\% (ABUD et al., 2009), o que pode ser manejado no interior da floresta por meio do sistema de podas, permitindo maior entrada de luz. Primeiramente é necessário desenvolvê-la e na área, cortar suas porções botânicas superiores, para então dispor sua biomassa no solo, enriquecendo os valores de $P$ no substrato (AMBROSANO et al., 2016). Além deste importante nutriente, a espécie é capaz de incorporar Ca e Mg em grande quantidade, diminuindo a acidez do solo por se tratarem de substâncias básicas, conforme afirmado por Ambrosano et al. (2016).

A fim de expandir a área de RL, a CA 1 apresenta grande potencial para se instaurar espécies frutíferas variadas devido à alta incidência luminosa, podendo ser cultivadas as nativas Acca sellowiana (Berg.) Burret (Goiabinha-serrana), E. uniflora, Vasconcellea quercifolia A.St.-Hil. (Mamãozinho-do-mato) e E. pyriformis Cambess. (Uvaia) com a comercialização dos frutos (SILVA, 2020; SCALON et al., 2001; MMA, 2011). Para tanto, $V$. quercifolia deve ser cultivada próxima à vegetação florestal devido à sua fragilidade quanto a temperaturas altas e dependência do fotoperíodo para o melhor desenvolvimento de suas estruturas botânicas (MMA, 2011). Na mesma CA é interessante implantar de forma integrada as espécies arbóreas fixadoras de $\mathrm{N}$ já ocorrentes na RL, expandindo sua população e garantindo-se a originalidade da floresta no novo fragmento a ser formado.

Como forma de total aproveitamento da incidência luminosa presente na CA 1, alguns cultivos alimentares rasteiros podem ser incorporados nas linhas de plantio, como alface, tomate, brócolis, couveflor, cenoura, beterraba, rabanete, repolho, alho-poró, aspargos, salsa, mandioca, além de espécies melíferas para atrair polinizadores, como o girassol. Para realizar os consórcios devem ser observados os efeitos antagônicos e sinérgicos que cada uma possui em suas relações. Assim, considerando-se as orientações de consórcios propostos por Primavesi (2016), deve-se plantar os tomateiros com aspargos, o repolho intercalado com mandioca, girassol e beterraba, e a couve-flor com salsa e alho-poró. Também, mandioca com feijão-fradinho e brócolis, repolho om rabanete, e alface com cenoura ou beterraba são boas indicações 
de consórcio de acordo com Aquino et al. (2005).

Tendo em vista os cultivos Ilex paraguariensis A.St.-Hil. (erva-mate), Persea americana Mill. (abacate) e Carya illinoinensis (Wang.) K. (noz-pecã) indicados pelo produtor rural entrevistado, é possível integrá-los no modelo de SAF, visto que são espécies de estratos arborescente e arbóreo, se manipulados por meio de podas de condução. Visto que a RL já contém floresta de estrato emergente, de maior sombreamento, a espécie I. paraguariensis poderia ser implantada na CA 1 em conjunto com espécies de maior porte, a fim de prezar pelo desenvolvimento de ramificações e aumento do tamanho das folhas, o que ocorre quando sombreada em até 50\% (FERRERA, 2015). P. americana, visto ser um cultivar que forma o sombreamento devido à sua estatura superior, pode ser intercalado com a erva-mate, evitando que esta seja prejudicada pelo sol pleno na CA 1. Para evitar que este atinja altura que dificulte a coleta dos frutos, é necessário realizar podas para frear o crescimento apical, prezando pela ramificação à altura adequada (ALMEIDA et al., 2016). Quanto à C. illinoinensis, conforme sua característica de boa adaptabilidade em ambientes divergentes, muito e pouco úmidos, se indica o seu cultivo na CA 1 como planta emergente, visto que pode atingir grandes alturas (RASEIRA, 1990).

\section{Modelo de SAF}

A partir das informações obtidas com as análises de solo, das espécies indicadas pela bibliografia, potenciais culturas inovadoras na região e cultivares almejados pelo produtor, foi possível elaborar o modelo de SAF na RL proposto no estudo, conforme Imagem 2, e uma segunda combinação de cultivares para a possível expansão da RL através da CA 1, atualmente utilizada como pastagem (Imagem 3). Se a implantação for efetivada, serão necessárias intervenções por meio de podas das nativas arbóreas e supressão das plantas exóticas, como H. dulcis (CAs 3, 5, 6, 9 e 10) e M. azedarach (CAs 2 e 8) para maior entrada de luminosidade, reutilizando-as para biomassa a longo prazo no SAF. As 13 espécies nativas já existentes e com potencial agroflorestal não estão incluídas no modelo, mas sua produção deverá ser considerada no momento da colheita, a fim de incrementar os lucros.

Inicialmente devem ser produzidos os adubos verdes, e no momento de incrementá-los no solo, iniciar o plantio dos cultivares selecionados. Portanto, o cronograma de plantios para o período primaveraverão segue com fisális, feijão-fradinho e mucuna-preta (MUNIZ et al., 2014; BEVILAQUA et al., 2007; AMBROSANO et al., 2016), e no período frio outono-inverno com as espécies mirtilo, morango-silvestre e feijão-de-porco (ANTUNES et al., 2006; ANTUNES et al., 2004; RAYOL et al., 2012). As frutíferas poderão ser plantadas a qualquer momento do ano, mas como as mesmas iniciam a produção dos frutos no fim do ano (GOMES et al., 2007), recomenda-se que o plantio ocorra no início do ano seguinte, época de verão, agilizando o desenvolvimento da muda, bem como a primeira colheita da produção. $\mathrm{O}$ espaçamento dos plantios deve ser de $3 \times 2$ m entre as frutíferas nativas propostas, guabiroba e cereja (MMA, 2011) $3 \times 1,5 \mathrm{~m}$ para o cultivar mirtilo (ANTUNES et al., 2006), $3 \times 1 \mathrm{~m}$ para morango-silvestre (ANTUNES et al., 2004), 1 × 1 m para fisális (RODRIGUES, 2018), 0,50 × 0,20 m para mucuna-preta (AMBROSANO et al., 2016), 1 × 0,20 m para feijão-fradinho (BEVILAQUA et al., 2007) e 1 x 0,5 m para feijão-de-porco (RAYOL et al., 2012), com 
algumas alterações para facilitar as associações dos cultivares.
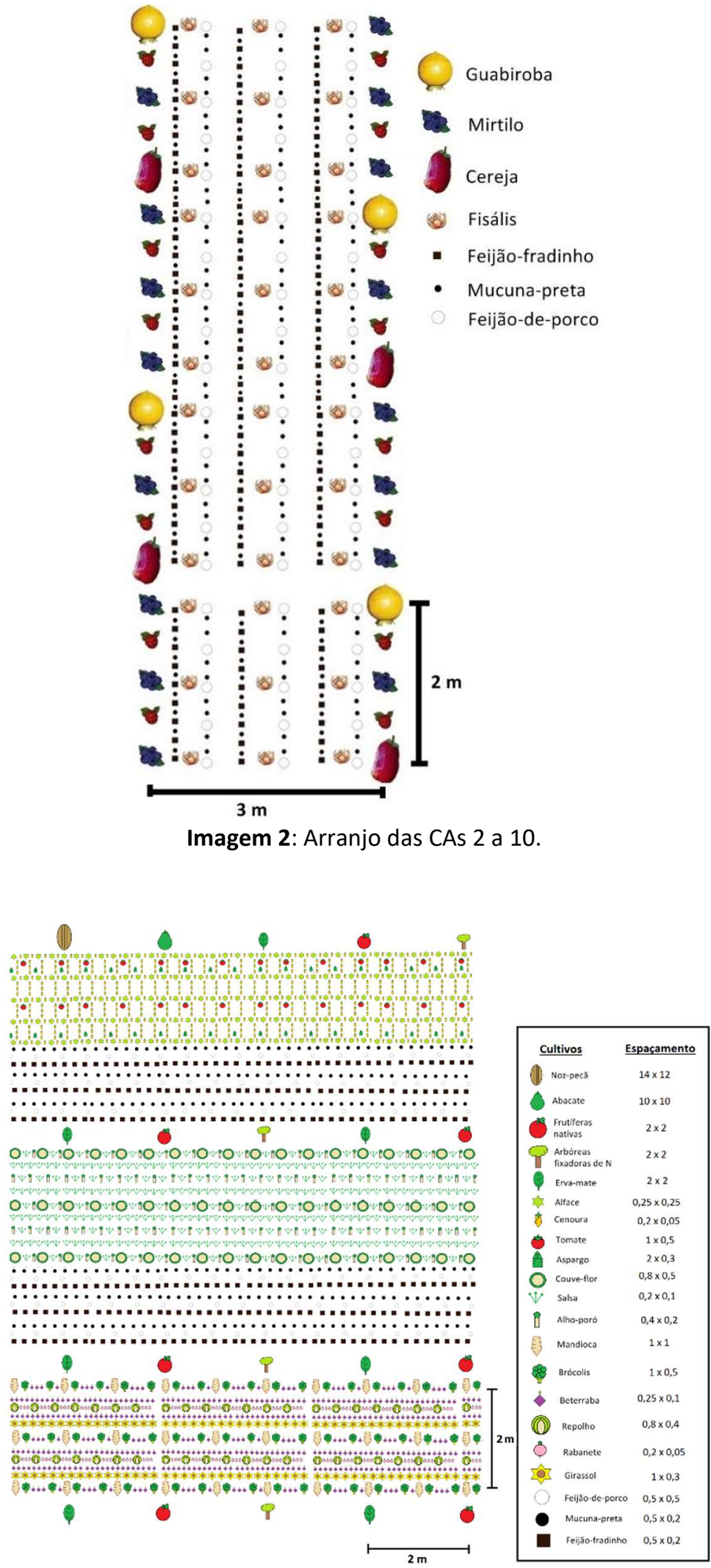

Imagem 3: Arranjo de SAF para expansão da RL na área de estudo.

Para a CA 1, visto não possuir vegetação arbórea que disponibilize $\mathrm{MO}$ em grandes quantidades, bem como ter ausência de espécies fixadoras de $\mathrm{N}$ e ser dependente de intervenção humana para o seu manejo, sugere-se preparar o solo com sua subsolagem e gradagem (KRONHARDT, 2018), retirando a porção de gramíneas e dando início ao cultivo dos adubos verdes já indicados para proteção do solo e reciclagem de 
nutrientes. Como forma de incorporar MO, é interessante dispor parte dos resíduos das podas na RL e da supressão das exóticas na CA 1. Quanto às épocas de plantio, sugere-se o cronograma de arbóreas, adubos verdes feijão-fradinho e mucuna-preta, hortaliças alface, brócolis, couve-flor, cenoura, beterraba, rabanete, repolho, alho-poró, mandioca, e girassol para o período primavera-verão (MMA, 2011; BEVILAQUA et al., 2007; AMBROSANO et al., 2016; BEVILACQUA, 2006; ZAFFARONI et al., 1998) e adubo verde feijão-de-porco, bem como as hortaliças alface, brócolis, couve-flor, cenoura, beterraba, rabanete, repolho, aspargo, tomate e salsa no período frio outono-inverno (RAYOL et al., 2012; BEVILACQUA, 2006). Os espaçamentos em metros entre os cultivares estão listados na Imagem 2, e seguem as indicações de Trani et al. (2013), MMA (2011), Bevilacqua et al. (2007), Rayol et al. (2012), Alves et al. (2014) e Bevilacqua (2006).

\section{CONCLUSÕES}

Por meio deste estudo veiculou-se que é possível propor um modelo de SAF em RL de propriedades rurais no Vale do Taquari/RS observando -se as bases agroecológicas, incrementando a renda familiar provida de um ambiente que o produtor comumente não observava como produtiva. Apesar da menor incidência luminosa comparando-se com áreas de monocultivo, a busca por cultivares adaptados a ambientes sombreados, ou que em sua natureza se encontram no estrato arbustivo e herbáceo, possibilita que os mesmos realizem suas funções e garantam a colheita de forma adequada e esperada. Quanto à área adjacente de pastagem estar interligada com a RL, torna-se interessante propor os consórcios agroflorestais, visto da possibilidade de expansão da floresta.

Os modelos de SAF propostos ofertam frutíferas nativas, incentivando o consumo de produtos da região, reforçando seu reconhecimento pela população local. Também, os indicados na RL geram produtos muito rentáveis no mercado, além de se observarem poucos produtores na região, valorizando-os. A escolha das espécies pertencentes a diferentes estratos permite que se tenham culturas de ciclos curtos e anuais, gerando receitas mais frequentes ao se comparar com monoculturas, onde o produtor recebe somente na colheita, normalmente anual ou bianual. Ressalta-se que as propostas agroflorestais são únicas para a área de estudo, podendo servir de base para orientar o desenvolvimento de posteriores modelagens em outros locais da região.

Além do benefício ao produtor, um SAF na região com produtos diferenciados e sem agrotóxicos auxilia na qualidade de vida dos consumidores, reforça a conscientização quanto à produção sem comprometer a ecologia local, além de incentivar outros produtores rurais a conhecer este método de plantio, bem como valorizar suas RL através do manejo sustentável. Caso for implantado, o SAF aferirá de forma positiva seu papel social, ambiental e econômico para o município.

\section{REFERÊNCIAS}

ABUD, H. F.; REIS, R. G. E.; TEÓFILO, E. M.. Caracterização morfológica de frutos, sementes plântulas e germinação de Mucuna aterrima Piper \& Tracy. Rev. Ciênc. Agron., v.40, n.4, p.563-569, 2009.
AGOSTINI, C.; BOURSCHEIDT, H. J.. A implementação do Programa de Aquisição de Alimentos nos municípios do Vale do Taquari (RS): uma análise da percepção dos executivos municipais. RESR, v.56, n.2, p.275-292, 2018. DOI: http://dx.doi.org/10.1590/1234-56781806-94790560206 
ALMEIDA, A.; COELHO, L. R.; PRIES, A. C. D.. Sistemas agroecológicos de produção de frutíferas. Taubaté: UNITAU, 2016.

ALMEIDA, C. M.; ARAÚJO, M. M.; LONGHI, S. J.; ROVEDDER, A. P.; SCCOTI, M. S. V.; D'ÁVILA, M.; AIMI, S. C.; TONETTO, T. S.. Análise de agrupamentos em remanescente de Floresta Estacional Decidual. Ciência Florestal, v.25, n.3., p.781-789, 2015. DOI: https://doi.org/10.5902/1980509819682

ALTIERI, M. A.. Agroecology: the science of sustainable agriculture. 2 ed. Boca Raton: CRC Press, 2018.

ALVES, G. M. R.; ALMEIDA, A. E. S.; MAGALHÃES, I. D.; COSTA, F. E.; COSTA, L. R.; SOARES, C. S.. Cultivo do girassol sob diferentes espaçamentos entre linhas no semiárido paraibano. Biofarm, v.10, n.3, p.14-19, 2014.

AMBROSANO, E. J.; WUTKE, E. B.; SALGADO, G. C.; ROSSI, F.; DIAS, F. L. F.; TAVARES, S.; OTSUK, I. P.. Caracterização de cultivares de Mucuna quanto a produtividade de fitomassa, extração de nutrientes e seus efeitos nos atributos do solo. Cadernos de Agroecologia, v.11, n.2, p.1-10, 2016.

ANTUNES, L. E. C.; RASEIRA, M. C. B.. Aspectos técnicos da cultura da amora-preta. Documentos 122. Pelotas: Embrapa Clima Temperado, 2004.

ANTUNES, L. E. C.; RASEIRA, M. C. B.. Cultivo do mirtilo (Vaccinium sp.). Pelotas: Embrapa Clima Temperado, 2006.

AQUINO, A. M.; ASSIS, R. L.. Agroecologia: princípios e técnicas para uma agricultura orgânica sustentável. Brasília: Embrapa informação Tecnológica, 2005.

ARAÚJO, E. A.; KER, J. C.; NEVES, J. C. L.; LANI, J. L.. Qualidade do solo: conceitos, indicadores e avaliação. Pesquisa Aplicada \& Agrotecnologia, v.5, n.1, p.187-196, 2012. DOI: http://doi.org/10.5777/PAeT.V5.N1.12

ARRUDA, M. R.; MOREIRA, D.; PEREIRA, J. C. R.. Amostragem e cuidados na coleta de solo para fins de fertilidade. Documentos, 115. Manaus: Embrapa Amazônia Ocidental, 2014.

ÁVILA, D. F.; GRIEBELER, M. P. D.; BRUM, A. L.. Inovação: a modernização da agricultura no Planalto Gaúcho (Brasil). UNOPAR Cient., Ciênc. Juríd. Empres., v.16, n.2, p.156-164, 2015. DOI: http://doi.org/10.17921/1517$\underline{9427.2015 \mathrm{v} 16 \mathrm{n} 2 \mathrm{p} 156-164}$

BENITES, V. M.; CARVALHO, M. C. S.; RESENDE, A. V.; POLIDORO, J. C.; BERNARDI, A. C. C.; OLIVEIRA, F. A.. Potássio, cálcio e magnésio na agricultura brasileira. In: PROCHNOW, L. I.; CASARIN, V.; STIPP, S. R.. Boas práticas para uso eficiente de fertilizantes. Piracicaba: IPNI, 2009, p.22-23.

BEVILACQUA, H. E. C. R.. Classificação das hortaliças. In: CASTANHEIRO, A. L. M.; BEVILACQUA, H. E. C. R.; SHIRAKI, J. N.. Horta: cultivo de hortaliças. São Paulo: SMVMA, 2006. p.1039-1042.

BEVILAQUA, G. A. P.; GALHO, A. M.; ANTUNES, I. F.; MARQUES, R. L. L.; MAIA, M. S.. Manejo de sistemas de produção de sementes e forragem de feijão-miúdo para a agricultura familiar. Documentos 204. Pelotas: Embrapa Clima Temperado, 2007.

BIONDO, E.; FLECK, M.; KOLCHINSKI, E. M.; SANT'ANNA, V.; POLESI, R. G.. Diversidade e potencial de utilização de plantas alimentícias não convencionais ocorrentes no Vale do Taquari, RS. Rev. Elet. Cient., v.4, n.1, p.61-90, 2018. DOI: http://dx.doi.org/10.21674/2448-0479.41.61-90

BORGES, A. L.; OLIVEIRA, A. M. G.; SOUZA, L. S.. Solos, nutrição e adubação. In: ALVES, E. J.. A cultura da banana: aspectos técnicos, socioeconômicos e agroindustriais. Cruz das Almas: Embrapa-CNPMF, 1997. p.197-260.

BONA, F. D.; MORI, C.; WIETHÖLTER, S.. Manejo nutricional da cultura de trigo. Informações Agronômicas, n.154, 2016.

BRASIL. Lei n. 11.947, de 16 de junho de 2009. Dispõe sobre o atendimento da alimentação escolar e do Programa Dinheiro Direto na Escola aos alunos da educação básica; altera as Leis nos 10.880, de 9 de junho de 2004, 11.273, de 6 de fevereiro de 2006, 11.507, de 20 de julho de 2007; revoga dispositivos da Medida Provisória no 2.178-36, de 24 de agosto de 2001, e a Lei no 8.913, de 12 de julho de 1994; e dá outras providências. Brasília: DOU, 2009.

BRASIL. Lei n. 12.651, de 25 de maio de 2012. Dispõe sobre a proteção da vegetação nativa; altera as Leis no 6.938 , de 31 de agosto de 1981, 9.393, de 19 de dezembro de 1996, e 11.428 , de 22 de dezembro de 2006; revoga as Leis no 4.771, de 15 de setembro de 1965, e 7.754, de 14 de abril de 1989, e a Medida Provisória no 2.166-67, de 24 de agosto de 2001; e dá outras providências. Brasília: DOU, 2012.

CAPORAL, F. R.; COSTABEBER, J. A.. Agroecologia: enfoque científico e estratégico. Agroecologia e Desenvolvimento Rural Sustentável, v.3, n.2, p.13-16, 2002.

CQFS. Comissão de Química e Fertilidade do Solo - RS/SC. Manual de adubação e de calagem para os Estados do Rio Grande do Sul e de Santa Catarina. Porto Alegre: EMBRAPACNPT, 2004.

DEGENHARDT, J.; FRANZON, R. C.; COSTA, R. R.. Cerejeirado-mato (Eugenia involucrata). Pelotas: Embrapa Clima Temperado, Documentos 211, 2007.

EMBRAPA. Empresa Brasileira de Pesquisa Agropecuária. Sistemas Agroflorestais: experiências e reflexões. Brasília: Embrapa Meio Ambiente, 2017.

FAQUIN, V.. Nutrição mineral de plantas. Dissertação (Mestrado em Solos e Meio Ambiente à Distância) Universidade Federal de Lavras, Lavras, 2005.

FEIX, R. D.; JORNADA, M. I. H.. Aglomeração produtiva de laticínios na região do Corede Vale do Taquari. Porto Alegre: FEE, 2015.

FERRERA, T. S.. Parâmetros fenométricos e qualidade da erva-mate em função do sombreamento, vento e cobertura vegetal do solo. Tese (Doutorado em Agronomia) Universidade Federal de Santa Maria, Santa Maria, 2015.

FILGUEIRAS, T. S.; BROCHADO, A. L.; NOGUEIRA, P. E.; GUALA, G. F.. Caminhamento: um método expedito para levantamentos florísticos qualitativos. Cadernos de 
Geociências, v.2, n.4, p.39-43, 1994.

FRANKE, I. L.; LUNZ, A. M. P.; AMARAL, E. F.. Metodologia para planejamento, implantação e monitoramento de sistemas agroflorestais: um processo participativo. Documentos, 49. Rio Branco: Embrapa, Acre, 2000.

GOMES, G. C.; RODRIGUES, W. F.; GOMES, F. R. C.; BARBIERI, R. L.; GARRASTAZU, M. C.. Conservação de frutíferas nativas: localização, fenologia e reprodução. Documentos, 183. Pelotas: Embrapa Clima Temperado, 2007.

GREGIO, J. V.; SILVA, R. K. A.; CANDIOTTO, L. Z. P.. Sistema Agroflorestal Sucessional: relato de uma experiência de implantação. Territórios, redes e desenvolvimento regional: perspectivas e desafios. Santa Cruz do Sul: UNISC, 2017.

IBGE. Instituto Brasileiro de Geografia e Estatística. Censo Agropecuário 2017: Resultados Definitivos. In: SIDRA. Sistema IBGE de Recuperação Automática. Tabelas Agricultura. Rio de Janeiro: IBGE, 2019.

IBGE. Instituto Brasileiro de Geografia e Estatística. Produção da Pecuária Municipal (PPM) 2018. 46 ed. Rio de Janeiro: IBGE, 2019.

JESUS, L.; RISSO, D.; SANTOS, K. F. A.; PEIXOTO, F. C.; SILVA, J. P.; LOPES, P.R.; SANTOS, W. S.; LOBO, S. C.; CALDAS, R. B.; NASCIMENTO, M. V.; LOPES, J. S.; SANTOS, J. D.; JESUS, M. O.. Potencial de áreas de assentamentos rurais no processo de construção de paisagens sustentáveis. Cadernos de Agroecologia, v.13, n.1, 2018.

KINUPP, V. F.. Plantas Alimentícias Não-Convencionais da região metropolitana de Porto Alegre, RS. Tese (Doutorado em Fitotecnia) - Universidade Federal do Rio Grande do Sul, Porto Alegre, 2007.

KRONHARDT, M. H.. Sistemas agroflorestais como proposta para a recuperação de áreas degradadas no RS, Brasil. Dissertação (Mestrado em Sistemas Ambientais Sustentáveis) - Universidade do Vale do Taquari Univates, Lajeado, 2018.

LEAL, M. L.; ALVES, R. P.; HANAZAKI, N.. Knowledge, use, and disuse of unconventional food plants. Journal of Ethnobiology and Ethnomedicine, v.14, n.6, p.1-9, 2018. DOI: http://doi.org/10.1186/s13002-018-0209-8

LIMA, D. K.. Frutas nativas como alternativa de renda: Guabiroba (Campomanesia xanthocarpa) na unidade de produção Nossa Senhora da Conquista, Goioxim-PR. Monografia (Bacharelado em Agronomia) - Universidade Federal da Fronteira Sul, Erechim, 2018.

LOSEKANN, M. E.. Caracterização, classificação e indicadores de qualidade do solo em localidades de agricultura familiar do estado do Rio Grande do Sul. Dissertação (Mestrado em Ciência do Solo) - Universidade Federal do Rio Grande do Sul, Porto Alegre, 2009.

LOURENÇO, F. S.; SILVA, M. R. M.; PINHEIRO, G. V.; ALVES, G. L.. Comportamento e desenvolvimento de adubos verdes em condições de sombreamento em um Sistema Agroflorestal. Cadernos de Agroecologia, v.13, n.1, 2017.

MACIEL, M. J.; BIRKHEUER, C. F.; REMPEL, C.. Qualidade físico-química e microbiológica do leite in natura: revisão sistemática. Natural Resources, v.8, n.1, p.17-30, 2018. DOI: http://doi.org/10.6008/CBPC2237-9290.2018.001.0003

MARKUS, E.; MORÁS, A. P. B.; FREITAS, E. M.; REMPEL, C. Análise estrutural da comunidade arbórea da mata ciliar de três cursos d'água em propriedades produtoras de leite do Vale do Taquari, RS. Pesquisas, Botânica, n.71, p.63-76, 2018.

MARTINS, C. R.; GOMES, C. B.; WOLFF, L. F.; CARDOSO, J. H. Leguminosas na fruticultura: uso e integração em propriedades familiares do sul do Brasil. Brasília: Embrapa, 2019.

MORGANTI JÚNIOR, A. J. M.; MAGRI, J. L.; FELIZARI, S. R.. Sistema Agroflorestal Cambona 4: um exemplo de impulso à sustentabilidade na Região Sul do Brasil. In: GRAMKOW, C.. Investimentos transformadores para um estilo de desenvolvimento sustentável: Estudos de casos de grande impulso (Big Push) para a sustentabilidade no Brasil. Brasilia: CEPAL, 2020. p.115-125.

MMA. Ministério do Meio Ambiente. Espécies nativas da flora brasileira de valor econômico atual ou potencial. Brasília: MMA, 2011

MUNIZ, J.; KRETZSCHMAR, A. A.; RUFATO, L.; PELIZZA, T. R.; RUFATO, A. R.; MACEDO, T. A.. General aspects of physalis cultivation. Ciência Rural, v.44, n.6, p.964-970, 2014. DOI: https://doi.org/10.1590/S0103-84782014005000006

NAIR, P. K. R.. The coming of age of agroforestry. J. Sci. Food Agric., v.87, p.1613-1619, 2007. DOI: http://doi.org/10.1002/jsfa.2897

NOLLA, A.; ANGHINONI, I.; CASTALDO, J. H.; ALVES, E. O. S.; MOTA-NETO, L. V.; SILVA, M. A. G.; MUNIZ, A. S. Disponibilidade de nutrientes e fitotoxidez de alumínio: influência da complexação por ligantes na solução do solo. Journal of Agronomic Sciences, v.4, p.1-16, 2015.

PARDON, P.; REUBENS, B.; REHEUL, D.; MERTENS, J.; FRENNE, P.; COUSSEMENT, T.; JANSSENS, P.; VERHEYEN, K.. Trees increase soil organic carbon and nutrient availability in temperate agroforestry systems. Agriculture, Ecosystems and Environment, v.247, p.98-111, 2017. DOI: http://dx.doi.org/10.1016/j.agee.2017.06.018

PICOLOTTO, L.; PEREIRA, I. S.; GONÇALVES, M. A.; VIGNOLO, G. K.; ANTUNES, L. E. C.. Adubação nitrogenada e potássica para cultura da amoreira-preta (Rubus spp.), na região de Pelotas/RS. In: SIMPÓSIO NACIONAL DO MORANGO, 6. Anais. Pelotas: Embrapa Clima Temperado, 2012.

PRIMAVESI, A.. Manual do solo vivo: solo sadio, planta sadia, ser humano sadio. 2 ed. São Paulo: Expressão Popular, 2016.

RASEIRA, A.. A cultura da nogueira-pecã (Carya illioensis) Pelotas: Embrapa Clima Temperado, 1990.

RAYOL, B. P.; ALVINO-RAYOL, F. O.. Produção de biomassa e teor de nutrientes do feijão-de-porco (Canavalia ensiformis (L.) DC.) em reflorestamento no estado do Pará. Agroecossistemas, v.4, n.2, p.85-90, 2012. DOI: http://dx.doi.org/10.18542/ragros.v4i2.1216 
REFLORA. Flora do Brasil 2020 em construção: Algas, Fungos e Plantas. Rio de Janeiro: Jardim Botânico do Rio de Janeiro, 2020.

REICHERT, L. J.; CARDOSO, J. H.; SCHIAVON, L. K.. Sistema Agroflorestal como alternativa de produção e geração de renda na agricultura familiar. Cadernos de Agroecologia, v.10, n.3, 2015.

REMPEL, C.; MORÁS, A. P. B.; BICA, J. B.; HERRMANN, M. F.. Flora arbórea e arborescente de Áreas de Preservação Permanente em propriedades rurais produtoras de leite no Vale do Taquari, Rio Grande do Sul, Brasil. Pesquisas, Botânica, v.71, p.29-45, 2018.

RIO GRANDE DO SUL. Perfil Socioeconômico COREDE Vale do Taquari. Porto Alegre: Secretaria do Planejamento, Mobilidade e Desenvolvimento Regional, Departamento de Planejamento Governamental, 2015.

RODRIGUES, M. H. B. S.. Caracterização fenológica, produtividade e maturação de frutos e sementes de Physalis peruviana L. Dissertação (Mestrado em Horticultura Tropical) - Universidade Federal de Campina Grande, Pombal, 2018.

SANTOS, H. G.; JACOMINE, P. K. T.; ANJOS, L. H. C.; OLIVEIRA, V. A.; LUMBRERAS, J. F.; COELHO, M. R.; ALMEIDA, J. A.; ARAÚJO-FILHO, J. C.; OLIVEIRA, J. B.; CUNHA, T. J. F.. Sistema Brasileiro de Classificação de Solos. 5 ed. Brasília: Embrapa, 2018.

SARTORI, D. B. S.; FONTINELLI, A. M.; MENEZES, H. M.; ELSENBACH, H.; MARENGO, R. P.; FONSECA, D. A. R.. Caracteres de produção de aveia branca em terras baixas sob diferentes densidades populacionais. In: SALÃO INTERNACIONAL DE ENSINO, PESQUISA E EXTENSÃO, 10. Anais. Santana do Livramento: Universidade Federal do Pampa, 2018.

SCALON, S. P. Q.; SCALON FILHO, H.; RIGONI, M. R.; VERALDO, F.. Germinação e crescimento de mudas de pitangueira (Eugenia uniflora L.) sob condições de sombreamento. Rev. Bras. Frutic., v.23, n.3, p.652-655, 2001. DOI: https://doi.org/10.1590/S010029452001000300042

SCHUSTER, N. S.. Diversidade florística e um sistema agroflorestal em Itati, Rio Grande do Sul. Monografia (Bacharelado em Ciências Biológicas) - Universidade Federal do Rio Grande do Sul, Porto Alegre, 2015.

SILVA, D. V.; BARBOSA, L. C. B. G.; BORGES, J. R. P.. A comercialização de produtos orgânicos: um olhar a partir das experiências existentes no Brasil. Monografia (Bacharelado o em Ciências Econômicas) - Universidade Federal de Alagoas, Santana do Ipanema, 2018.

SILVA, F. C.; SILVA, C. A.; BERGAMASCO, A. F.; RAMALHO, A. L.. Disponibilidade de micronutrientes em cinco solos em função do tempo de incubação de um composto de lixo. Engenharia Agrícola, v.26, n.1. p.224-234, 2006.

SILVA, L. R.. Alterações morfofisiológicas em feijão (Acca sellowiana) sob diferentes níveis de sombreamento. Dissertação (Mestrado em Agronomia) - Universidade
Tecnológica Federal do Paraná, Pato Branco, 2020.

SILVA, R. C.; PEREIRA, J. M.; ARAÚJO, Q. R.; PIRES, A. J. V.; DEL REI, A. J.. Alterações nas propriedades químicas e físicas de um Chernossolo com diferentes coberturas vegetais. Revista Brasileira de Ciências do Solo, v.31, p.101-107, 2007. DOI: https://doi.org/10.1590/S0100$\underline{06832007000100011}$

SOBRAL, L. F.; BARRETTO, M. C. V.; SILVA, A. J.; ANJOS, J. L.. Guia prático para interpretação de resultados de análise de solo. Documentos, 206. Aracaju: Embrapa Tabuleiros Costeiros, 2015

SOBRAL, M.; JARENKOW, J. A.; BRACK, P.; IRGANG, B.; LAROCCA J.; RODRIGUES, R. S.. Flora Arbórea e

Arborescente do Rio Grande do Sul. 2 ed. São Carlos: RiMa, 2013.

SOUZA, V. C.; TOLEDO, C. P.; SAMPAIO, D.; BÍGIO, N. C.; COLLETTA, G. D.; IVANAUSKAS, N. M.; FLORES, T. B.. Guia das plantas da Mata Atlântica: Floresta Estacional. Piracicaba: Liana, 2019.

STRATE, M. F. D.; CONTERATTO, M. A.. Práticas de agroindustrialização e arranjos produtivos locais como estratégia de diversificar e fortalecer a agricultura familiar no Rio Grande do Sul. Redes, Santa Cruz do Sul, v.24, n.1, p.277-245, 2019. DOI: http://doi.org/10.17058/redes.v24i1.13052

STRATE, M. F.; COSTA, S. M.. Quintais produtivos: contribuição à segurança alimentar e ao desenvolvimento sustentável de mulheres rurais no RS/Brasil. Braz. J. of Develop., v.4, n.7, p.3732-3744, 2018

STRECK, E. V.; KÄMPF, N.; DALMOLIN, R. S. D.; KLAMT, E.; NASCIMENTO, P. C.; SCHNEIDER, P.; GIASSON, E.; PINTO, L. F. S.. Solos do Rio Grande do Sul. Porto Alegre: RS-ASCAR, 2008.

TEJERO, I. P. T.; MILECH, R. F.. Produção de milho em propriedades familiares da fronteira sul. Revista Agropampa, v.1, n.1, p.21-34, 2016.

TEN CATEN, A.; SAFANELLI, J. L.; SILVA, W. C.. Adequação do pacote soiltexture para classificação textural do solo pela linguagem R.. In: CONGRESSO BRASILEIRO DE CIÊNCIA DO SOLO, 35. Anais. Natal: SBCS, 2015.

APG; CHASE, M. W.; CHRISTENHUSZ, M. J. M.; FAY, M. F.; BYNG J. W.; JUDD, W. S.; SOLTIS, D. E.; MABBERLEY, D. J.; SENNIKOV, A. N.; SOLTIS, P. S.; STEVENS P. F.. An update of the Angiosperm Phylogeny Group classification for the orders and families of flowering plants: APG IV.. Botanical Journal of the Linnean Society, v.181, n.1, p.1-20, 2016. DOI: https://doi.org/10.1111/boj.12385

VALDUGA, M.. Controle de custos aplicados na produção de leite e frango de corte em uma propriedade rural do Vale do Taquari. Monografia (Bacharelado em Ciências Contábeis) - Universidade do Vale do Taquari, Lajeado, 2018.

VILLAR, M. L. P.. Manual de interpretação de análise de plantas e solos e recomendação de adubação. Série Documentos n. 35. Cuiabá: EMPAER-MT, 2007. 
WREGE, M. S.; STEINMETZ, S.; REISSER-JÚNIOR, C.; ALMEIDA,

I. R.. Atlas climático da região Sul do Brasil: estados do

Paraná, Santa Catarina e Rio Grande do Sul. Brasília:

Embrapa, 2012
ZAFFARONI, E.; GRIGOLO, S. C.. Determinação da época de plantio do girassol na região Sul do Rio Grande do Sul. Rev. Bras. de Agrociência, v.2, n.2, p.138-142, 1998.

A CBPC - Companhia Brasileira de Produção Científica (CNPJ: 11.221.422/0001-03) detém os direitos materiais desta publicação. Os direitos referem-se à publicação do trabalho em qualquer parte do mundo, incluindo os direitos às renovações, expansões e disseminações da contribuição, bem como outros direitos subsidiários. Todos os trabalhos publicados eletronicamente poderão posteriormente ser publicados em coletâneas impressas sob coordenação da Sustenere Publishing, da Companhia Brasileira de Produção Científica e seus parceiros autorizados. Os (as) autores (as) preservam os direitos autorais, mas não têm permissão para a publicação da contribuição em outro meio, impresso ou digital, em português ou em tradução. 